\title{
Remediation of Nickel from Crude Oil Obtained from Bomu Oil Field Using Cassava Waste Water Starch Stabilized Magnetic Nanoparticles
}

\author{
Joshua L. Konne ${ }^{1} \&$ Kenneth Okpara ${ }^{1}$ \\ ${ }^{1}$ Department of Chemistry, Rivers State University of Science \& Technology, Port Harcourt, Nigeria \\ Correspondence: Joshua L. Konne, Department of Chemistry, Rivers State University of Science \& Technology, \\ Port Harcourt, Nigeria. Tel: 234-81-3677-3590. E-mail: konne.joshua@ust.edu.ng
}

Received: October 12, 2013 Accepted: December 16, 2013 Online Published: January 6, 2014

doi:10.5539/eer.v4n1p25

URL: http://dx.doi.org/10.5539/eer.v4n1p25

\begin{abstract}
Starch Stabilized Magnetic Nanoparticles (SSMNPs) were prepared by reacting $4.4 \mathrm{~g}$ of $\mathrm{FeCl}_{3} \cdot 6 \mathrm{H}_{2} \mathrm{O}$ with $1.98 \mathrm{~g}$ of $\mathrm{FeCl}_{2} .4 \mathrm{H}_{2} \mathrm{O}$ in $61 \mathrm{~mL}$ of $0,0.025,0.5,0.1$ and $0.5 \% \mathrm{w} / \mathrm{v}$ of cassava waste water starch solution. Deionised water $(0 \%$ $\mathrm{w} / \mathrm{v}$ ) was used as the control. Powder X-ray diffraction analysis of the first four samples confirmed that all the samples contained magnetite nanoparticles with estimated sizes of $16.99,15.73,11.48$ and $17.73 \mathrm{~nm}$ respectively. The SSMNPs were then applied in the removal of nickel ions from crude oil obtained from Bomu oil field. The samples were divided into batches A and B. Both samples were shaken for $3.3 \mathrm{~h}$ but only batch A was centrifuged before analysis. $0.2 \mathrm{~mL}$ of each sample was siphoned and dissolved in $n$-hexane for analysis. The results obtained showed that the sample with the least starch concentration $(15.73 \mathrm{~nm})$ recorded the best performance in both cases with 56 and $93 \%$ of $\mathrm{Ni}$ (II) complexes removal respectively. All measurements were done using a UV-VIS spectrophotometer set at $\lambda_{\max }$ of $400 \mathrm{~nm}$ predetermined from a scan of $\mathrm{Ni}$ (II) ions solution.
\end{abstract}

Keywords: starch, cassava-waste-water, magnetic nanoparticles, nickel, crude oil

\section{Introduction}

Nickel, a ferromagnetic metal is one of the trace metals found in crude oil and particularly in Bomu oil field crude as reported by Onojake, Oforka and Osuji (2011). Trace metals from parent rocks got incorporated into crude oil in the form of porphyrin complexes which originated from the chlorophyll components of decayed biomass. This is responsible for higher concentrations of nickel found in oils formed from sedimentary marine organic matter than those from other terrestrial biomass. Bomu crude and terrain fell in this category (because of salt water coastline). High nickel concentration of $8.93 \mathrm{ppm}$ has been reported for Bomu crude by the same author (Onojake et al., 2011).

Similarly, other authors have reported different concentrations of nickel in some Nigeria crude oils. These include: - Bonny light crude 0.13-0.17 ppm (Odebunmi \& Adeniyi, 2004), Onshore/off-shore Nigeria crude oil 210-1620 ppb (Muhammad et al., 2013) and 351-11000 ppb also cited in the same paper. The different reports showed marked variation in nickel concentrations of Nigeria crude oil due to factors such as source of the crude oil, sample handling and the method of analysis (Odebunmi \& Adeniyi, 2004). The analytical techniques used in the two reports were HPLC and AAS respectively.

The presence of nickel in crude oil is generally undesirable because of the following reasons; it accelerates the corrosion of distillation towers and turbines (Odebunmi \& Adeniyi, 2004), catalytic poisoning during refining processes with resultant undesirable side reactions that compromised efficiency (Welz \& Vale, 2012). In addition the inhalation of nickel dust or aerosols generated during the combustion of crude oil is also harmful to humans as a potential carcinogen. Other ailments and disease conditions such as bronchitis, skin reactions, stomach and blood disorder, asthma, lung and heart disorders could also be linked to prolonged exposure.

Coking and hydrotreatment are some pre-treatment methods of processing heavy crude in order to remove metal ions, sulphur and nitrogen compounds (Reynolds, 2004). However, due to the avoidance of high carbon, coke is usually applied in limited quantity which doesn't guarantee efficient removal of trace metals from crude.

In a drive for more effective and cheaper processes, Reynolds (2004) treated surrogate metal ions bound to petroporphyrin fractions isolated from heavy crude with some chemical agents followed by washing in aqueous solutions to remove the metals. The author monitored the process using UV-VIS spectrophotometer $\left(\lambda_{\max }=410\right.$ 
$\mathrm{nm}$ ) and found that maleic acid in dimethyl formamide completely removed vanadyl porphyrin while both nickel and vanadyl porphyrin removals were achieved by the use of superacids (fluorosulfonic acid and trifluoromethane sulfonic acid).

In a similar approach, Wen, Yang, Xu and Gao (2013) removed nickel and vanadium from crude oil using microwave-chemical method with $35 \%$ efficiency in the presence of $500 \mathrm{mg} / \mathrm{L}$ demetallizers (synthesized from polyethylene and polyamides) at $70{ }^{\circ} \mathrm{C}$ and 5 min reaction time. The efficiency was increased to 43.41 and $41.63 \%$ for nickel and vanadium respectively at $30 \mathrm{~min}$ reaction time. The nickel and vanadium concentrations were measured using infrared spectroscopy.

Starch Stabilized Magnetic Nanoparticles (SSMNPs) have been applied recently in the remediation of arsenic contaminated soil with higher efficiency recorded for the starch-stabilized adsorbents than the non SSMNP (Zhang, Pan, Zhao, \& He, 2011; An, Liang, \& Zhao, 2011). Arsenate adsorption on the SSMNPs was found to be generally starch concentration dependent except for the $0.5 \%$ concentration that behaved somewhat different. The authors attributed the success to greater adsorption surface and stronger adsorption affinity of SSMNPs to arsenate ions. It would be expected that nickel (II) porphyrin complex in crude oil would require adsorbent with high surface area due to its bulky nature hence, the use of SSMNPs with high surface area and strong affinity could be promising. In addition magnetic nanoparticles would exert stronger affinity for ferromagnetic elements like nickel from crude oil. Secondly, SSMNPs are more environmentally benign and cheaper adsorbents than most of the methods in use.

The use of UV-VIS spectrophotometer in monitoring the depletion of nickel from Bomu crude oil would also provide some quantitative data from this technique for the first time. To date, there seemed to be no report on the use of starch-stabilized magnetic nanoparticles (SSMNPs) obtained from cassava waste water for the remediation of nickel from crude oil in the available literature. Cassava waste water is the major by-product of cassava processing and an abundant waste in Niger Delta region of Nigeria. This report presents the first application of SSMNPs in the remediation of nickel from Bomu crude.

\section{Experimental}

\subsection{Preparation of Magnetic Iron Oxide Particles}

The preparation of magnetic iron particles was done by the method reported in literature with slight modifications (Zhang et al., 2011). $4.4 \mathrm{~g}$ of $\mathrm{FeCl}_{3} \cdot 6 \mathrm{H}_{2} \mathrm{O}$ and $1.98 \mathrm{~g}$ of $\mathrm{FeCl}_{2} \cdot 4 \mathrm{H}_{2} \mathrm{O}$ were dissolved in $61 \mathrm{~mL}$ of de-aerated water to precipitate the iron oxide. The solution was purged for 30 mins with nitrogen gas in order to create the inert environment needed to prevent the oxidation of $\mathrm{Fe}^{2+}$ species. $143 \mathrm{~mL}$ of $0.7 \mathrm{M} \mathrm{NaOH}$ was added drop wise to the mixture with the aid of a syringe with further influx of $\mathrm{N}_{2}$ for additional 10 mins and continuous shaking for $1 \mathrm{~h}$. The mixture was allowed to stand for $24 \mathrm{~h}$. The colour of the mixture changed from brown to dark brown and finally to black during the first $7 \mathrm{~h}$. The $\mathrm{NaOH}$ increased the $\mathrm{pH}$ to 11 which supplied the basified environment for magnetite formation according to the following equation:

$$
2 \mathrm{Fe}^{3+}{ }_{(a q)}+\mathrm{Fe}^{2+}{ }_{(a q)}+8 \mathrm{OH}^{-}{ }_{(a q)} \rightarrow \mathrm{Fe}_{3} \mathrm{O}_{4(s)}+4 \mathrm{H}_{2} \mathrm{O}_{(l)}
$$

The clearer supernatant of the mixture was decanted away followed by confirmatory magnetization test of the bottom black portion with a bar magnet. The black magnetic iron oxide particles were attracted to the sides of the sample bottle when a bar magnet was brought closer to it. The resultant precipitates (black magnetic iron oxide particles) were allowed to stay in contact with the mother liquor in capped bottles in order to minimised further oxidation of the product.

\subsection{Preparation/Characterization of Starch Stabilized Magnetic Nanoparticles (SSMNP)}

The SSMNPs were prepared by the dissolution of $0,0.025,0.05,0.10$ and $0.5 \%(\mathrm{w} / \mathrm{v})$ dried starch powder in 100 $\mathrm{mL}$ of deaerated deionized water with vigorous stirring until a uniform mixture was obtained. $61 \mathrm{~mL}$ of the mixture was used as solvent for the preparation of ten (10) SSMNPs (two replicates for each concentration) following the same method described for magnetic iron oxide particles. Four of the samples (0 to 0.10$)$ were dried at $120^{\circ} \mathrm{C}$ in the laboratory oven and sent for powder X-ray analysis at Sheda Science and Technological Complex (SHESTCO) Abuja, Nigeria. The instrument used was A PAnalytical Pro MPD XRD facility on a Reflection-Transmission Spinner configuration. Minimum step size of 2-Theta: 0.001 and $\mathrm{CuK} \alpha$ radiation source was used for the analysis. Particle size estimations were done by feeding the generated full width at half maximum (FWHM) from the reflection patterns to the Scherrer formula (Patterson, 1939). 


$$
L=\frac{\kappa \lambda}{\beta \cos \theta}
$$

Where $\mathrm{L}=$ Linear particle dimension, $\kappa=$ shape, factor $=0.93 \AA, \beta=$ FWHM in degrees and $\theta$ in degrees respectively.

\subsection{Application of SSMNP for Nickel Removal}

The ten SSMNPs samples were divided into two batches. $0.5 \mathrm{~g} / \mathrm{v}$ of the different SSMNPs and the control (0\%) were mixed with $10 \mathrm{~mL}$ of crude oil and shaken for $3.3 \mathrm{~h}$ at $800 \mathrm{rpm}$ using a 65800 Thermolyne Maxi shaker. Batch A samples were centrifuged at $2000 \mathrm{rpm}$ for $30 \mathrm{mins}$ while batch B samples were allowed to stand before analysis. $0.2 \mathrm{ml}$ of each sample was siphoned with a micro syringe and dissolved in $10 \mathrm{~mL}$ of $n$-hexane for spectrophometric analysis of nickel.

\subsection{Wavelength Selection and Calibration of UV-VIS Spectrophotometer}

The wavelength of maximum adsorption $\left(\lambda_{\max }\right)$ of nickel ions was determined by a scan of $0.02 \mathrm{M}$ nickel sulphate hexahydrate solution in a $1 \mathrm{~mL}$ cuvette from 350 to $500 \mathrm{~nm}$ range using a UV-VIS spectrophotometer, model 2500 LaboMed, Inc. This was followed by a calibration curve of varying concentrations of nickel (II) ions at the same wave length. The slope (molar absorptivity) obtained was used in the determination of the concentrations of the absorbing nickel ions in the samples.

\section{Results and Discussion}

The preparation of starch-stabilized magnetic nanoparticles resulted in the formation of the desired products according to Equation 1. Preliminary confirmation tests were the observed black colour (Figure 1a) of the products and subsequent attraction to a bar magnet. The magnetic particles (control) crude oil-mixture can be seen in the middle of the four test samples (SSMNPs-crude oil-mixtures) of Figure 1b. The powder X-ray reflection patterns of the four samples (Figure 2) were all indexed to the $\mathrm{Fe}_{3} \mathrm{O}_{4}$ phase in the following order: control (A) and $\mathrm{Fe}_{3} \mathrm{O}_{4}+0.025$ (B), $\mathrm{Fe}_{3} \mathrm{O}_{4}+0.05$ (C) and $\mathrm{Fe}_{3} \mathrm{O}_{4}+0.10$ (D) starch concentrations. The peak positions and intensity were similar to literature data (Kim, 2004). The plots were done without background correction and could be responsible for the noisy background.
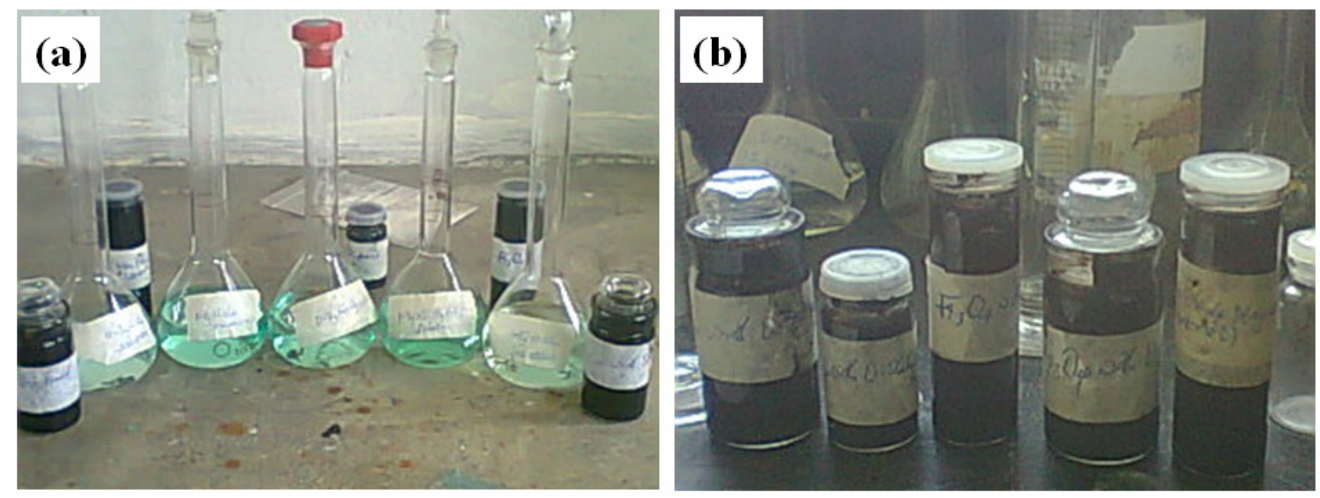

Figure 1. Varying concentrations of (a) SSMNPs (black) in small sample bottles beside $\mathrm{Ni}^{2+}$ ions in volumetric flasks and (b) Magnetic particles $\left(\mathrm{Fe}_{3} \mathrm{O}_{4}\right)$-middle and SSMNPs + crude oil samples

However, few impurity phases marked ( ) were also observed for the samples. Peak broadening due to decrease in particle size and increase in amorphous content (starch particles) were observed with the starch loaded magnetic nanoparticles. The sizes were estimated to be 16.99, 15.73, 11.48 and $17.73 \mathrm{~nm}$ for samples A-D respectively from Scherrer formula. Particle size was found to decrease with increase in the starch concentration except for D which showed an abnormal increase. Similar observation has been reported for a $0.05 \%$ starch concentration and this was attributed to the $\mathrm{NaOH} /$ starch ratio that would result in higher starch hydrolysis at higher starch concentrations.

The $\lambda_{\max }$ obtained from a scan of $0.02 \mathrm{M}$ nickel ions solution between 350 to $500 \mathrm{~nm}$ intervals was determined as 0.19 at $400 \mathrm{~nm}$ (Figure 3). The result compared closely to 401 and $410 \mathrm{~nm}$ for nickel (II) ions and complex respectively, reported previously (Kumar, Reddy, \& Reddy, 2007; Okoye, Chukwuneke, Ekere, \& Ihedioha, 
2013). The molar absorptivity obtained from the calibration curve (plot of absorbance vs concentration of 0.02 , $0.04,0.06,0.08$ and $1.0 \mathrm{M}$ nickel (II) ions) at $400 \mathrm{~nm}$ was $5.23 \mathrm{M}^{-1} \mathrm{~cm}^{-1}$. The aqueous light green solutions of the $\mathrm{Ni}^{2+}$ ions are shown in Figure 1a. A good linear regression $\left(\mathrm{R}^{2}\right)$ of 0.9958 implied that the result was in good agreement with Beer-Lambert's law. However, slight deviations from Beer-Lambert's law at concentrations greater than $0.01 \mathrm{M}$ are normal (Harris, 2003). The calibration plot showed these deviations at 0.06 and $0.1 \mathrm{M}$ nickel (II) ions (Figure 4).

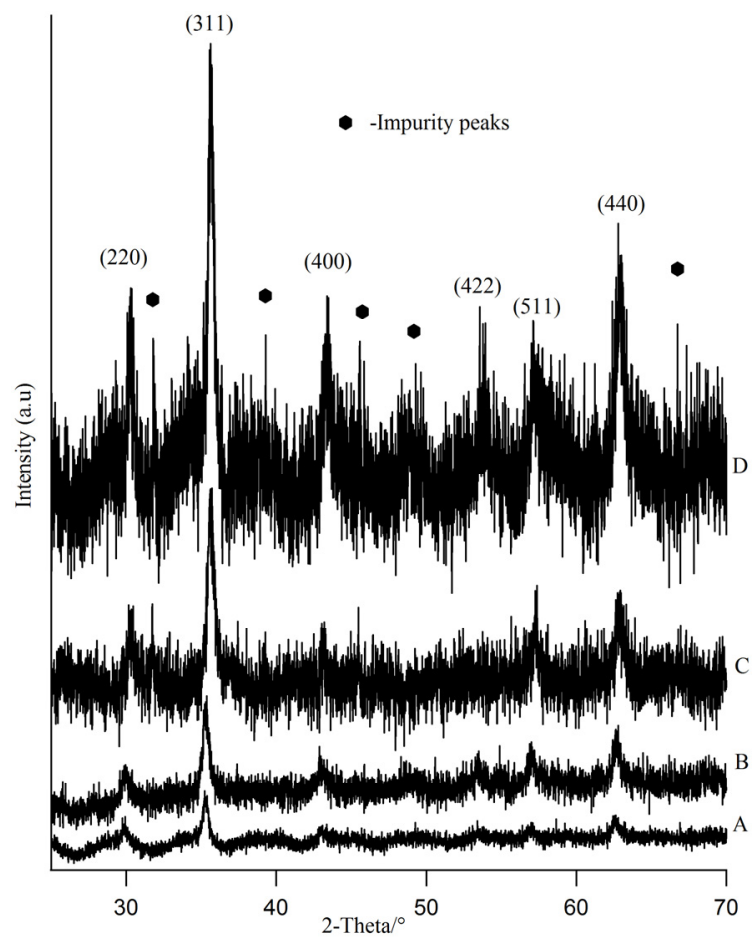

Figure 2. XRD of A- $\mathrm{Fe}_{3} \mathrm{O}_{4}$ (control), $\mathrm{B}-\mathrm{Fe}_{3} \mathrm{O}_{4}+0.025$ starch, $\mathrm{C}-\mathrm{Fe}_{3} \mathrm{O}_{4}+0.05$ starch and $\mathrm{D}-\mathrm{Fe}_{3} \mathrm{O}_{4}+0.10$ starch concentrations showing indexed magnetite patterns and some impurity peaks

Table 1 showed the calculated concentrations and percentages of nickel (II) complexes in crude oil (c), crude oil with magnetic particles $(\mathrm{c}+\mathrm{m})$ and crude oil with varying concentrations of SSMNPs $(\mathrm{c}+\mathrm{m}+0.025 \ldots \mathrm{c}+\mathrm{m}+$ 0.1 ). The results showed that the magnetic particles effectively removed 55 and $24 \%$ concentration of nickel from the Bomu crude oil for batches A and B respectively. This result was greater than $53 \%$ previously reported for the removal of $\mathrm{Ni}$ from petroporphyrin-rich fractions and asphaltenes by biocatalytic method (Mogolloñ, Rodríguez, Larrota, Ortiz, \& Torres, 1998).

Table 1. Samples, calculated concentrations and percentages of $\left[\mathrm{Ni}^{2+}\right]$ left after removal

\begin{tabular}{lcccc}
\hline Samples & $\begin{array}{c}\text { Conc-A } \\
\left(\mathbf{M o l d m}^{-3}\right)\end{array}$ & $\mathbf{A - \%}\left[\mathbf{N i}^{\mathbf{2 +}}\right]$ & $\begin{array}{c}\text { Conc-B } \\
\left(\mathbf{M o l d m}^{-3}\right)\end{array}$ & $\mathbf{B - \%}\left[\mathbf{N i}{ }^{2+}\right]$ \\
\hline $\mathrm{c}$ & 0.1091 & 100 & 0.1091 & 100 \\
$\mathrm{c}+\mathrm{m}$ & 0.0491 & 45 & 0.0829 & 76 \\
$\mathrm{c}+\mathrm{m}+0.025$ & 0.0484 & 44 & 0.0076 & 7 \\
$\mathrm{c}+\mathrm{m}+0.050$ & 0.1072 & 98 & 0.0359 & 33 \\
$\mathrm{c}+\mathrm{m}+0.10$ & 0.1206 & 111 & 0.2771 & 254 \\
$\mathrm{c}+\mathrm{m}+0.50$ & 0.1084 & 99 & 0.2209 & 202 \\
\hline
\end{tabular}

Table 1 shows the concentrations of nickel (II) ions left in samples and their relative percentages to the original concentration in crude before the removal process. 
The higher efficiency recorded in batch A $(c+m)$ showed that centrifugation increased the sticking probability of the adsorbates to the magnetic particles and quicker coalescing of nickel porphyrin complexes to the bottom of the centrifuge tubes due to centrifugal force than those of batch B where interactions were limited to surface adsorption on the magnetic layer. This was responsible for the observed differences between batch A and B (c + m) results.

However, the efficiency in batches A and B increased to 56 and 93\% respectively when SSMNPs of $0.025 \% \mathrm{w} / \mathrm{v}$ concentrations were applied. The use of starch in the preparation of magnetic particles effectively reduced particle aggregations that led to slight particle size reduction (16.99 to $11.48 \mathrm{~nm})$, provided functionalised particle surfaces and stabilizing effect. The particle sizes of the samples produced agreed with previous report by Zhang et al. (2011), howbeit, the control sample (A) was smaller. Therefore increase in surface area of the SSMNPs (adsorbents) was responsible for the observed increase in efficiency when SSMNPs were involved.

The overall results showed that the least starch concentration produced the best result in both cases studied. Batch B also produced a second higher efficiency of $67 \%$ at $0.05 \% \mathrm{w} / \mathrm{v}$ starch concentration. This means that higher surface coverings reduced the attractions of the magnetic core of SSMNPs to the outermost layers (over certain critical length scales) and created some loosely bound layers which might have caused the interference that resulted in loss of efficiency. Hence there was virtually no reduction observed at higher starch concentrations rather anomalous concentration values above $100 \%$ were obtained particularly for batch $\mathrm{B}$. But when the system was centrifuged, the loosely bound layers coalesced and settled to the bottom of the centrifuge tubes reducing interference as observed in batch A results. The higher efficiencies (67 and 93\%) observed in batch $\mathrm{B}$ can also be linked to the fact that the presence of $\mathrm{Ni}^{2+}$ in crude as porphyrin complexes (central metal ion complex) favoured layer by layer attraction and adsorption. Therefore more layers settled to the surfaces of the adsorbent at lower starch concentrations under gravity/magnetic attraction in B than in a more agitated batch A system.

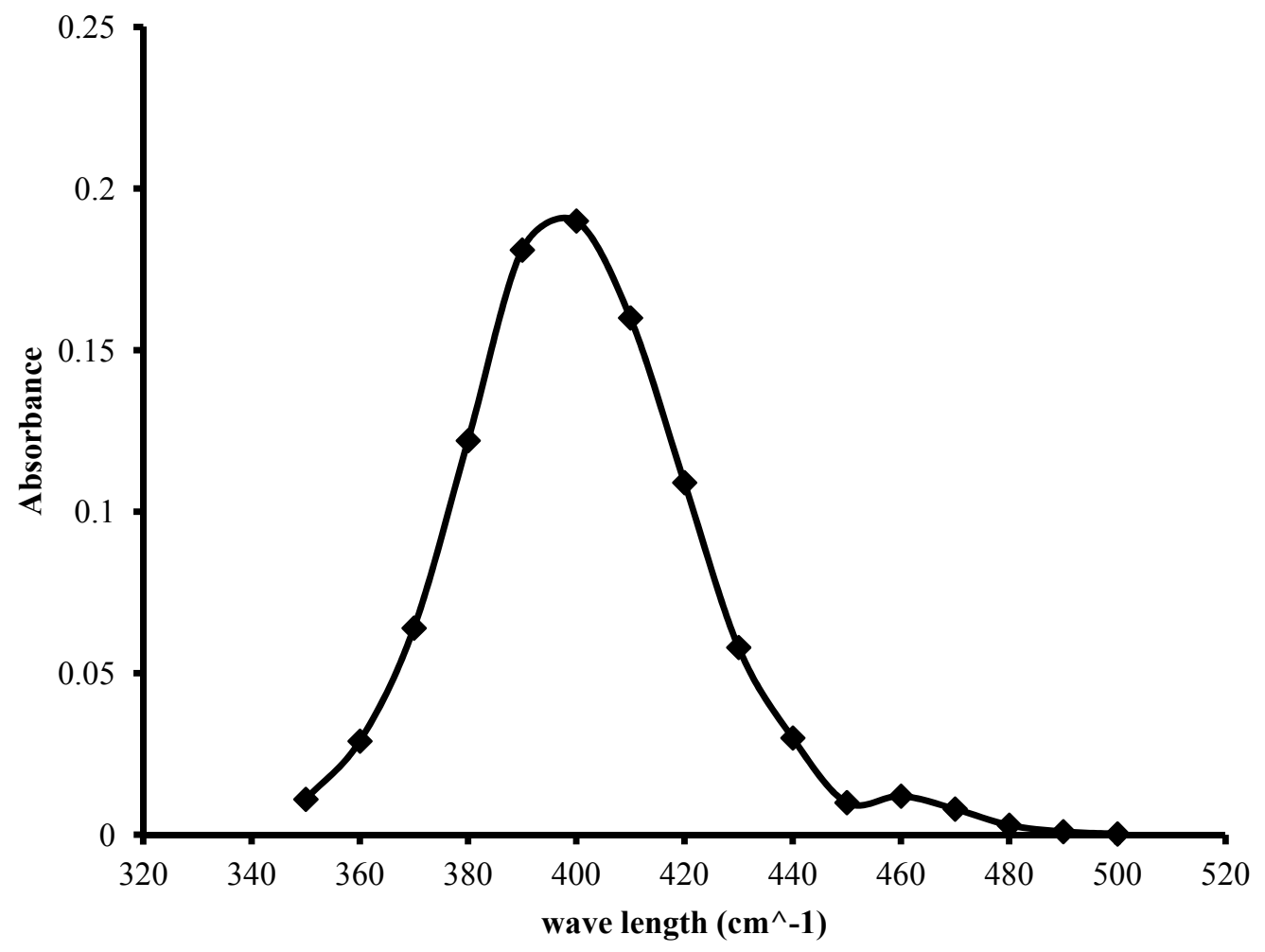

Figure 3. Absorbance vs wavelength of nickel (II) ions 


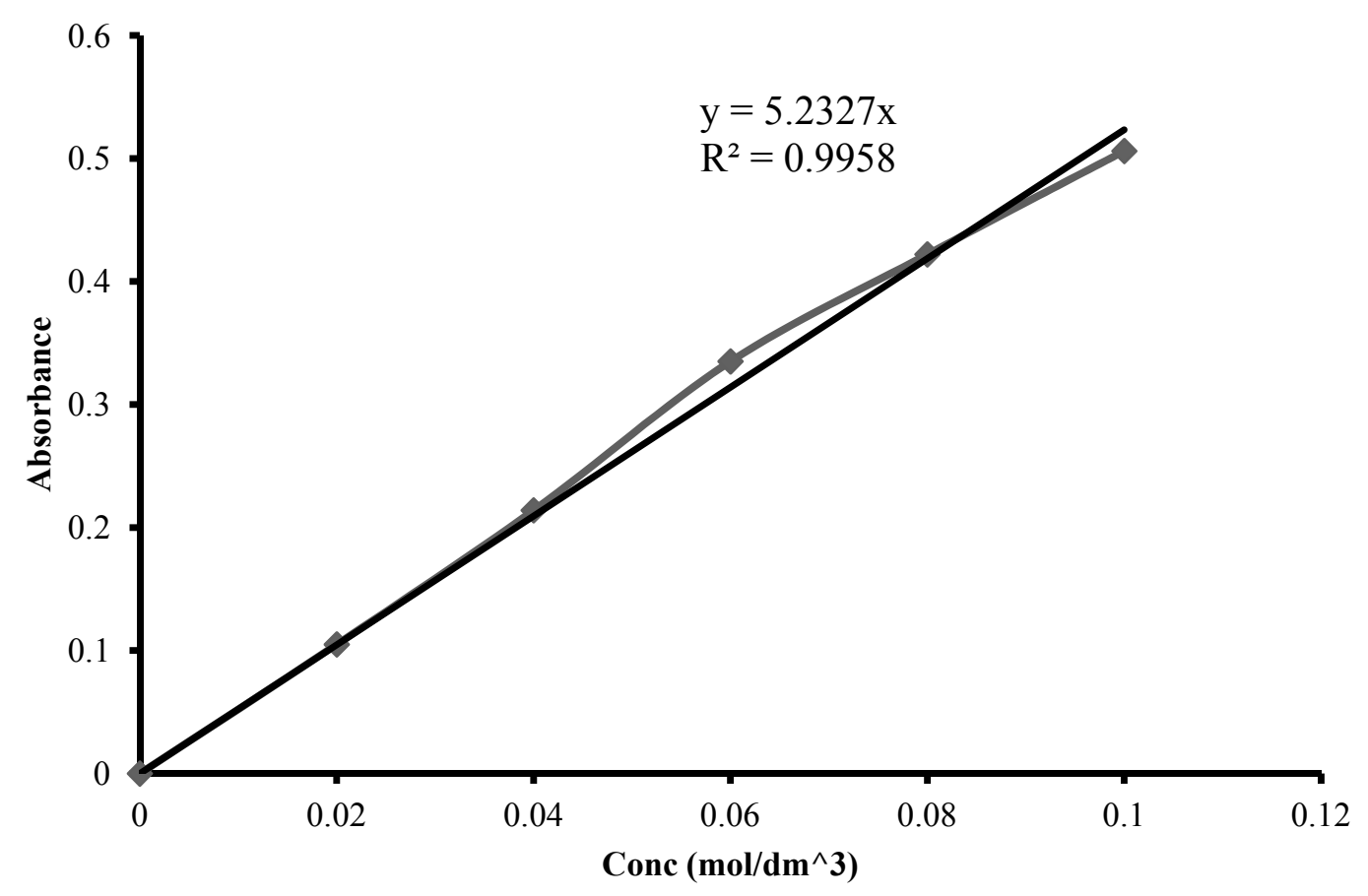

Figure 4. Absorbance vs concentration plot of Ni (II) ions at $400 \mathrm{~nm}$

\section{Conclusion}

SSMNPs have been tested and shown to be more effective in the removal of nickel porphyrin complexes from Bomu crude oil than any other methods reported previously. The results showed that the sample with the least starch concentration exhibited the strongest attraction and surface affinity for nickel complexes in crude oil with up to $93 \%$ of nickel complexes removal. The use of SSMNPs in adsorption studies are currently being investigated in our laboratories. More work is needed on studying the effectiveness of SSMNPs in the removal of other trace metals in crude oil.

\section{Acknowledgements}

The authors wish to thank Mr. Bob Manuel of the Department of Chemistry, Rivers State University of Science and Technology Port Harcourt, Nigeria for his technical support on the UV-VIS spectrophotometer. We also wish to acknowledge Sheda Science and Technological Complex (SHESTCO) Abuja, Nigeria for the Powder X-ray analysis.

\section{References}

An, B., Liang, Q., \& Zhao, D. (2011). Removal of arsenic (V) from spent ion exchange brine using a new class of starch-bridged magnetite nanoparticles. Water research, 45(5), 1961-1972. http://dx.doi.org/10.1016/j.watres.2011.01.004

Harris, D. C. (2003). Quantitative Chemical Analysis (6th ed.). W. H. Freeman and Company.

Kim, C. S. (2004). Crystallographic and Magnetic Properties of Iron Oxide Nanoparticles for Applications in Biomedicine. Journal of Magnetics, 9(3), 83-85.

Kumar, A. P., Reddy, P. R., \& Reddy, V. K. (2007). Spectrophotometric determination of Nickel (II) with 2-hydroxy-3-methoxybenzaldehyde thiosemicarbazone. Indian J. Chem., 46A, 1625-1629. http://dx.doi.org/10.4283/JMAG.2004.9.3.083

Mogolloń, L., Rodriguez, R., Larrota, W., Ortiz, C., \& Torres, R. (1998). Biocatalytic removal of nickel and vanadium from petroporphyrins and asphaltenes. Applied biochemistry and biotechnology, 70(1), 765-777. http://dx.doi.org/10.1007/BF02920187

Muhammad, I., Ikeh, P. O., Usman, B. B., Shehu, B. D., Salawu, K., \& Mikailu, D. A. (2013). Determination of Vanadium, Nickel, Copper and Iron as Complexes of Bis-Acetylpivalyl Methane (Ethylene Diamine) in Nigerian onshore and offshore Crude Oils Using HPLC. Journal of Natural Sciences Research, 3(8), 105-111. 
Odebunmi, E. O., \& Adeniyi, S. A. (2004). Characterization of crude oil and Petroleum products for trace elements. J. Chem. Soc. Nigeria, 29, 149-154.

Okoye, C. O. B., Chukwuneke, A. M., Ekere, N. R., \& Ihedioha, J. N. (2013). Simultaneous ultraviolet-visible (UV-VIS) spectrophotometric quantitative determination of $\mathrm{Pb}, \mathrm{Hg}, \mathrm{Cd}, \mathrm{As}$ and $\mathrm{Ni}$ ions in aqueous solutions using cyanidin as a chromogenic reagent. International Journal of Physical Sciences, 8(3), 98-102.

Onojake Mudiaga, C., Oforka Nicolas, C., \& Osuji Leo, C. (2011). Trace Metals Geochemistry of Crude Oils from Umutu/Bomu Fields in South West Niger Delta Nigeria. Energy and Environment Research, 1, 139-146. http://dx.doi.org/10.5539/eer.v1n1p139

Patterson, A. L. (1939). The Scherrer formula for X-ray particle size determination. Physical review, 56(10), 978. http://dx.doi.org/10.1103/PhysRev.56.978

Reynolds, J. G. (2004). Removal of nickel and vandium from heavy crude oils by exchange reactions. Prepr. Pap.-Am. Chem. Soc., Div. Fuel Chem, 49, 79.

Welz, B., \& Vale, M. G. R. (2012). Determination of Total Nickel and Vanadium and Their Volatile and Thermally Stable Species in Crude Oil Using High- Resolution Continuum Source Graphite Furnace Atomic Absorption Spectrometry. Analytical Instrumentation, 14.

Wen, Z., Yang, J., Xu, X., \& Gao, J. (2013). Removal of Nickel and Vanadium from Crude Oil by Microwave-Chemical Method. I. Chemical Method. Petroleum Science and Technology, 31(9), 991-999. http://dx.doi.org/10.1080/10916460903330023

Zhang, M., Pan, G., Zhao, D., \& He, G. (2011). XAFS study of starch-stabilized magnetite nanoparticles and surface speciation of arsenate. Environmental Pollution, 159(12), 3509-3514. http://dx.doi.org/10.1016/j.envpol.2011.08.017

\section{Copyrights}

Copyright for this article is retained by the author(s), with first publication rights granted to the journal.

This is an open-access article distributed under the terms and conditions of the Creative Commons Attribution license (http://creativecommons.org/licenses/by/3.0/). 